\title{
Abordagem para Implantação de Testes baseada no TMM e em Práticas Ágeis
}

\author{
Juliana Ochner ${ }^{1}$, Alexandre Vasconcelos ${ }^{1}$, Roberto Mendes ${ }^{1}$ \\ ${ }^{1}$ Centro de Informática - Universidade Federal de Pernambuco (UFPE) \\ Recife - PE - Brasil \\ $\{j \circ$, amlv, rdm\}@cin.ufpe.br
}

\begin{abstract}
Resumo. Este artigo descreve uma abordagem para implantação de testes de software baseada no TMM e em práticas ágeis com o objetivo de viabilizar a melhoria e implantação de processos de testes em empresas que necessitam de resultados rápidos e com poucos investimentos. Para a validação da abordagem, ela foi aplicada em duas empresas de desenvolvimento de software. Este artigo apresenta a abordagem desenvolvida, uma aplicação prática e as conclusões.
\end{abstract}

\begin{abstract}
This paper describes an approach to improve software test process based on TMM and agile practices in order to make feasible the improvement and implementation of software test process on the organizations that need fast results with low costs. To validate the approach, it was applied in two software companies. This article presents the developed approach, a practical application and conclusions.
\end{abstract}

\section{Introdução}

Nas últimas décadas, indústrias de software têm investido um esforço substancial na melhoria da qualidade de seus produtos. Este tem sido um trabalho difícil, já que o tamanho e a complexidade do software aumentam rapidamente, os usuários e clientes estão se tornando mais exigentes e o mercado cada vez mais competitivo [Vasconcelos et al, 2006].

Pensando nisso, muitas empresas estão buscando implantar ou melhorar seus processos de teste. Com o intuito de facilitar a melhoria de processo de software, diversos modelos têm surgido nas últimas décadas. São modelos que fornecem diretrizes para guiar iniciativas de programas de melhoria de software, tais como IDEAL [McFeeley, 1996], ISO/IEC 15504 [ISO 15504, 2005] e Pro2Pi [Salviano, 2006]. Existem também modelos de referência específicos para a definição de requisitos necessários a um Processo de Testes, tais como: TMM ( Test Maturity Model) [Burnstein, 2003], TIM (Test Improvement Model) [Ericson, 1996] e TPI (Test Process Improvement) [Koomen, 1999].

Embora tenham surgido tais modelos grande parte da indústria de software ainda apresenta muitas dificuldades em realizar um programa de melhoria de processo de testes de software efetivo. Isto ocorre por uma série de motivos, conforme descrito em [Niazi, 2003], [MCT_01, 2001], [Santana, 2007] e [Carosia, 2003]. Dentre estes motivos, há o fato dos modelos de melhoria ser genéricos e exigirem diversas 
adaptações para tratar as dificuldades comumente encontradas em um programa de melhoria de testes. Adaptar, para a necessidade da organização, um modelo detalhado não é uma tarefa fácil, pois é necessário um conhecimento do modelo completo para que sejam escolhidas quais atividades serão realmente úteis. Devido ao grande escopo e ao alto grau de detalhamento destes modelos de melhoria, esta é uma tarefa bastante trabalhosa e complexa. Brodman [Brodman, 1994] afirma que um número alto de programas de melhoria de software baseado em modelos como CMM [Humphrey, 1989] e IDEAL falham e que 53\% dos casos de falha estão relacionados à complexidade e tamanho destes modelos. Por outro lado, modelos de referência específicos, como o TMM, não fornecem o "como fazer" fornecem somente "o que fazer" para que a empresa possa atingir um dos seus níveis de maturidade.

Diante deste cenário, foi elaborada uma abordagem simples e ágil, utilizando pra isso práticas ágeis, que combine os benefícios dos modelos de melhoria de processo com os benefícios fornecidos pelos modelos de referência em testes, no nosso caso o TMM, que foi escolhido por ser o modelo focado em testes mais conhecido [Freesz, 2004], [Reffson, 2006], [Santos, 2006]. Tal abordagem deve atender as necessidades das empresas, que necessitam melhorar seus processos de testes rapidamente mesmo, possuindo todas as limitações apresentadas acima, para conseguir competir no mercado do qual elas fazem parte.

Além desta seção introdutória, este artigo está organizado nas seguintes seções: a seção 2 descreve a abordagem proposta; a seção 3 descreve o estudo de caso realizado e a seção 4 as conclusões.

\section{Abordagem AITS}

A abordagem AITS (Abordagem para Implantação de Teste de Software) foi elaborada para um contexto caracterizado por organizações intensivas em software com processos de testes de baixa maturidade, que queiram iniciar um ciclo de melhoria de teste o mais rápido possível, investindo poucos recursos e com resultados de curto prazo. Ela é uma adaptação do modelo de melhoria IDEAL e específica para o contexto de implantação de processo de teste de software, utilizando o TMM [Burnstein, 2003] como modelo base de referência para o programa de melhoria e inserindo práticas ágeis presentes no Scrum [Schwaber, 2004] e XP [Beck, 1999].

A abordagem definida está organizada em fases, atividades e templates ${ }^{1}$ conforme exibido na figura 1. Algumas fases definidas estão inseridas em uma iteração. Cada iteração terá a duração máxima de 30 dias aproximadamente, conforme definido no Scrum. A adoção desta prática na abordagem se faz necessária para apresentar resultados em um curto espaço de tempo para a organização, motivar os envolvidos com o programa de melhoria e diminuir a resistência em relação às mudanças propostas, já que os benefícios estarão sendo percebidos ao final de cada iteração.

1 Todos os templates mencionados neste artigo podem ser visualizados através do site: http://www.cin.ufpe.br/ jo/dissertacao_jo_versao_final.pdf 


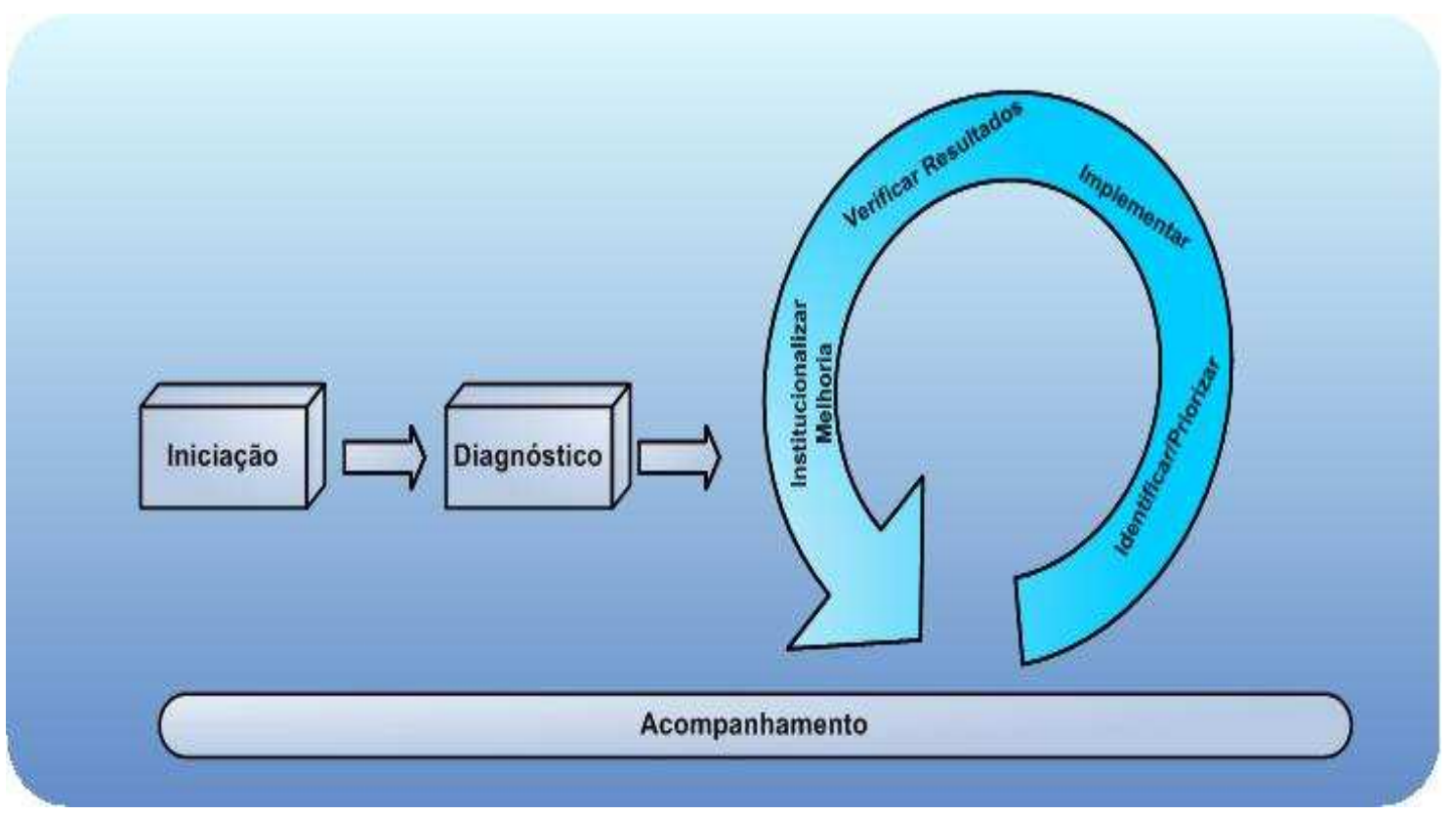

Figura 1 - Ciclo da abordagem AITS

Para a sua aplicação prática, a abordagem necessita que um pequeno time de condutores seja formado para coordenar e conduzir todas as fases durante um programa de melhoria. As pessoas que farão parte do time de condutores deverão possuir preferencialmente os seguintes requisitos para que a abordagem seja aplicada corretamente: experiência em qualidade de software e modelos de melhoria de processos, conhecimento sobre testes de software, boa influência e respeito na organização, boa comunicação.

O time de condutores deve possuir preferencialmente as seguintes características:

- Ter entre 2 e 3 integrantes. É necessário que haja troca de idéias e conhecimentos entre os integrantes do time de condutores. Acredita-se que o time de condutores também não deve ter um número alto de integrantes, 3 seria um número máximo ideal, para que o time não perca o foco do trabalho. Além disso, os times de testes são geralmente pequenos, o que torna desnecessário a formação de um time de condutores com muitas pessoas.

- Cada integrante deverá dedicar pelo menos 50\% da sua jornada de trabalho para a condução do programa de melhoria através da abordagem. Isto ocorre porque, na maioria das vezes, os integrantes do time de condutores têm um acúmulo de papéis por causa da falta de recursos financeiros da organização, por isso a abordagem não exige dedicação integral do condutor no programa, mas sua dedicação deve ser pelo menos $50 \%$ para que o programa tenha um bom andamento. Não é indicado que nenhum participante do programa de melhoria trabalhe mais do que 8 horas diárias, pois isso pode prejudicar fortemente o seu desempenho no programa. Assim, o princípio de "Ritmo Sustentável" de XP deve ser seguido pelos participantes do programa de melhoria.

- Conhecimentos sobre a Abordagem AITS.

O time de testes não deve ser superior a 12 pessoas, conforme utilizado no XP e no Scrum. A adoção desta prática se faz necessária para maximizar a comunicação entre 
todos os membros do time e manter o feedback constante entre eles, com o aumento da equipe torna-se difícil manter uma comunicação efetiva.

\subsection{Fase 1 - Inicialização}

Esta fase é iniciada a partir do momento que a alta direção decide iniciar um programa de melhoria na organização. É nela que a alta direção entende a necessidade, se compromete e define o contexto para o programa de melhoria. Nela o comprometimento da alta direção é obtido. As atividades envolvidas nesta fase são:

Obter Comprometimento dos Interessados: Os interessados no programa de implantação de testes devem estar comprometidos com o programa, para isto, é necessário: reconhecer e entender o estímulo para a melhoria, verificar objetivos de negócio da organização, estabelecer o contexto para a melhoria, obter o comprometimento da alta direção e dos principais interessados.

Kickoff do Projeto: O programa de melhoria deve ser encarado pelos envolvidos como um projeto, que tem início, meio e fim. Todos os envolvidos devem estar cientes qual é o objetivo do programa, quais as dificuldades e benefícios que este programa trará para a empresa. Uma apresentação deve ser realizada para toda a empresa para fornecer informações sobre o programa de melhoria de testes para todos os envolvidos. Esta apresentação deve ser realizada para que todos os envolvidos obtenham ciência do programa de melhoria, sintam-se parte dele e o conheça como um todo. Com isso, espera-se que todos se sintam beneficiados com o sucesso do programa de melhoria e estejam estimulados para que isso aconteça. Assim, os princípios de "Posse Coletiva" e "Time Inteiro" utilizados no XP são aplicados nesta atividade.

\subsection{Fase 2 - Diagnóstico}

O principal objetivo desta fase é entender o processo de testes atual utilizado pela empresa, assim como as interações organizacionais e como tudo isso contribui com o negócio da organização. As atividades desta fase são:

Realizar Diagnóstico: esta atividade tem como principal objetivo realizar a avaliação da situação e do processo de testes atual da organização. A avaliação é realizada pelo time de condutores, baseada em um checklist elaborado a partir das práticas e sub-práticas definidas no modelo de maturidade em testes TMM para os níveis 2 e 3. Entrevistas com representantes-chaves das áreas de testes, requisitos e planejamento de projeto são realizadas.

Compilar Resultados: A partir das observações resultantes da avaliação é atribuída uma nota a cada pergunta que indica desde o não atendimento a esta pergunta ao completo atendimento. Com isso, é possível compilar os resultados do diagnóstico, identificando os pontos fortes e as oportunidades de melhorias levantados e corroborados nas entrevistas. Com os resultados do diagnóstico, o time de condutores deverá classificar o processo de testes avaliado em um dos dois níveis de maturidade do TMM considerado por este trabalho. Para ajudar o trabalho dos condutores e evitar erros na classificação de maturidade do processo, o próprio checklist de avaliação determina automaticamente $^{2}$ em qual nível do TMM aquele processo se encaixa, seguindo as notas

\footnotetext{
${ }^{2} \mathrm{O}$ checklist automático foi elaborado no excel.
} 
atribuídas. O processo de classificação seguido pelo checklist de avaliação é muito semelhante ao algoritmo de classificação definido do TMM. Abaixo é descrito o processo de classificação utilizado pelo checklist de avaliação da abordagem AITS:

- Questões que tiveram as opções "Não se Aplica" ou "Não Sei" selecionadas não serão consideradas para avaliação, ou seja, serão retiradas do cálculo. Estas opções deverão ser utilizadas em casos extremamente particulares não podendo representar mais do que $10 \%$ das respostas do checklist de avaliação para não comprometerem o resultado da avaliação.

- As opções "Não", "Parcialmente" e "Sim" correspondem aos seguintes pesos 0, 1 e 2 respectivamente no resultado da avaliação do processo de teste.

- O Resultado Final é dado da seguinte maneira: se o total de pontos adquiridos nas questões para cada área de processo do TMM for maior ou igual a 70\% dos pontos válidos, a área de processo avaliada será considerada como satisfeita. Se todas as áreas de processo do nível forem satisfeitas, o processo de teste será considerado Aprovado naquele determinado nível do TMM. Caso contrário, será considerado como Reprovado. Ressaltando que para o processo de testes seja considerado no nível 3 do TMM, será necessário que ele satisfaça todas as áreas de processo dos níveis 2 e 3.

O critério de aprovação do AITS é considerado bastante arrojado se comparado com o TMM-AM. Isto se deve ao fato do checklist possuir um menor número de questões que conseguem atender as sub-práticas do TMM, fazendo com que estas questões tenham maior representatividade e peso frente às sub-práticas que elas representam. Além disso, o checklist de avaliação da AITS possui a opção "Parcialmente", o que pode elevar a pontuação final da avaliação se considerado com o TMM-AM que não possui esta opção.

Apresentar Diagnóstico: Deve ser elaborado um relatório final da avaliação contendo os resultados do diagnóstico, este relatório é apresentado à alta direção da empresa. Deve ser também realizada uma apresentação contendo um resumo da avaliação para todos os membros diretamente envolvidos com a área de testes e com programa de melhoria. Esta atividade tem como principal objetivo fornecer uma visão geral do processo de teste atual para todos os interessados no programa. É muito importante que esta apresentação seja realizada para estimular a comunicação e o feedback contínuo entre os integrantes do programa de melhoria e obter um entendimento comum em relação ao estado atual do processo de teste da organização. Nesta atividade são aplicados os princípios de Comunicação e Feedback presentes no XP.

- Template do Checklist: Este template foi elaborado a partir de uma adaptação do questionário de avaliação do TMM-AM níveis 2 e 3 . A principal diferença entre os dois documentos é que o checklist da AITS foi customizado para se tornar um artefato mais simples e mais objetivo, possibilitando um melhor entendimento das questões por parte dos entrevistadores e dos entrevistados, tornando assim, a fase de avaliação mais dinâmica e fornecendo uma compreensão mais rápida aos interessados no programa. O checklist de avaliação da AITS possui 64 questões que cobrem todos os objetivos estabelecidos nas áreas de processo do TMM níveis 2 e 3, enquanto o questionário de avaliação apresentado no TMM-AM possui 104 questões para cobrir os mesmos objetivos. Isto se deve ao fato de que algumas questões do 
TMM-AM não foram consideradas no questionário de avaliação da AITS por não serem relevantes para o contexto definido neste trabalho. Além disso, algumas questões do TMM-AM também foram diluídas ao longo do checklist de avaliação da AITS. É importante ressaltar que embora o checklist tenha sido adaptado, ele mantém a cobertura em relação a todos os objetivos definidos pelo TMM nos níveis citados.

- Template do Relatório Final da Avaliação e Template da Apresentação da Avaliação.

\subsection{Fase 3 - Identificar e Priorizar Ações de Melhoria}

O objetivo desta fase é identificar e priorizar as ações a serem estabelecidas em cada iteração do programa de melhoria de testes da organização. Para isto, os resultados da fase de diagnóstico devem ser considerados. Após a primeira iteração finalizada, as análises e experiências passadas também devem ser observadas.

Identificar Ações: Identificar as ações que devem ser realizadas para que os pontos de melhoria levantados sejam resolvidos. Um template com ações padrões foi elaborado baseado em experiências anteriores de melhoria de processos de testes e as ações aderentes às práticas do TMM níveis 2 e 3. Ações padrões não podem ser substituídas ou removidas, pois todas as ações existentes no documento têm uma relação direta com as práticas do TMM. Sendo assim, é necessário que elas sejam implementadas para que a empresa atinja o nível desejado do TMM.

Priorizar Ações: as ações a serem tomadas deverão ser priorizadas através de critérios que determinarão quais ações devem ser consideradas mais urgentes para a organização e deverão estar nas primeiras iterações do plano de ação. É importante ressaltar que as ações referentes às práticas do TMM nível 2 terão maior prioridade em relação às ações do TMM nível 3 por serem mais básicas e darem suporte para ações do nível 3. Por isso, a pré-priorização e a priorização final só fazem sentido para ações que estão no mesmo nível do TMM.

É necessário que a priorização final seja feita com base nos seguintes critérios pra cada ação: análise SWOT [Johnson, Scholes e Sexty, 1989], benefícios esperados com sua implementação para a organização, custo de implementação desta ação, interdependência em relação a outras ações. Um template foi elaborado para avaliar a priorização final das ações considerando todos os critérios citados.

A pontuação final é derivada do somatório da pontuação obtida em cada critério apresentado. Em caso de empate, fica a critério dos condutores escolherem a ação mais prioritária. A priorização das ações se faz necessária para definir o escopo de entrega de cada iteração, priorizando as ações que possuem mais urgência para a organização. Com isso, nesta atividade é feita a aplicação do princípio "Jogo do Planejamento" utilizado no XP. As ações pertencentes às próximas iterações constituem o backlog do programa de melhoria aplicando o mesmo conceito de backlog utilizado no Scrum.

Elaborar Plano de Ação: Esta atividade consiste em elaborar um plano de ação iterativo e incremental, este plano deve considerar as práticas priorizadas e agrupadas por iterações. As práticas mais prioritárias devem estar nas primeiras iterações do plano. É fortemente recomendado que no máximo 10 ações sejam selecionadas por iteração, a fim de que a equipe de testes não seja sobrecarregada em suas atividades e as mudanças 
sejam introduzidas gradativamente utilizando o princípio de "Pequenas Versões" presente no XP. O template do plano de ação definido é divido em iterações, e as iterações são constituídas por ações. O plano ainda contempla a execução de um projeto piloto ao final de cada iteração.

Templates: Template de Ações Padrões, Template de SWOT, Template de Priorização, Template Plano de Ação.

\subsection{Fase 4 - Implementar Ações de Melhoria}

O objetivo desta fase é colocar em prática as ações de melhoria planejadas de acordo com o plano de ação.

Executar Ações: Uma vez que o plano de ação foi estabelecido, é necessário implementar as ações planejadas. Nesta fase, deverá ser incluída também a execução do piloto, a fim de avaliar e exercitar o entendimento da equipe em relação às novas ações. Os artefatos gerados durante a execução dos pilotos não devem ser reaproveitados para os projetos, afim de que as pessoas se sintam confortáveis para aprender, errar e corrigir. É nesta atividade que os integrantes do time de teste junto com o time de condutores irão testar e darão os aceites em relação às ações implementadas, eles irão analisar quais ações são passíveis de utilização no dia-a-dia da organização. Com isso, o princípio do XP "Pequenas Versões" é utilizado nesta atividade, pois a cada nova iteração, um conjunto pequeno de ações é disponibilizado aos participantes para que eles possam utilizar e testar as ações através dos projetos pilotos. Outro princípio do XP presente nesta atividade é o princípio "Testes de Aceitação", uma vez que a equipe já utilizou as ações, eles junto com o time de condutores estão aptos para escolher as ações que serão agregadas ao processo de teste da organização.

Templates : Não se aplica

\subsection{Fase 5 - Verificar Resultados e Aprender}

Nesta fase é importante que experiências sejam capturadas e documentadas, bem como os benefícios adquiridos e problemas enfrentados durante a iteração atual. Estas informações devem ser disponibilizadas aos principais envolvidos com o programa de melhoria de testes.

Verificar Resultados: nesta atividade é importante que lições aprendidas sejam coletadas, analisadas e documentadas. A coleta das informações deve ser realizada através de uma reunião com todos os envolvidos na iteração atual do programa de melhoria de testes e questões como: "O que deu certo? E o que poderia ter sido melhor?" devem ser respondidas nesta reunião por cada um dos participantes. O objetivo principal desta atividade é levantar oportunidades de melhoria para a próxima iteração que será iniciada. Após o término da reunião, o time de condutores deve documentar os resultados obtidos através de um documento formal. Nesta atividade é utilizado o conceito "Reunião de Retrospectiva da Sprint" definido no Scrum.

Apresentar Resultados: Os resultados da iteração atual devem ser apresentados pelo time de condutores a todos os envolvidos com o programa de melhoria de testes, e também para a alta direção da empresa. As dificuldades levantadas e benefícios da iteração também devem ser apresentados. Se a iteração atual for a última iteração do programa de melhoria, todos os resultados alcançados durante o programa devem ser 
apresentados e relacionados com os objetivos de negócios levantados durante a fase de iniciação. Um nível do TMM também deve ser identificado para a empresa com a finalização do programa. Esta atividade é essencial para mostrar aos envolvidos, os resultados alcançados por eles na iteração, as dificuldades enfrentadas e etc. Isto auxilia no estabelecimento de uma comunicação forte e contínua entre todos do time, motiva os envolvidos e principalmente a alta direção, pois eles conseguem enxergar os resultados obtidos em um curto espaço de tempo. Com isso, os valores "Comunicação" e "Feedback" do XP estão fortemente presentes nesta atividade.

Templates: Template de Lições Aprendidas, Template de Apresentação de Resultados.

\subsection{Fase 6 - Institucionalizar a Melhoria}

O objetivo desta fase é institucionalizar as ações de melhoria que deram resultados positivos nas fases anteriores. Estas ações que deram certo devem ser refletidas no processo de testes da organização.

Institucionalizar a Melhoria: todas as melhorias que foram implementadas na iteração e obtiveram resultados positivos, devem ser refletidas no processo de testes da organização. As ações são agregadas ao processo de teste ao final de cada iteração, inserindo mudanças gradativas e incrementais, diminuindo assim a resistência às mudanças, diminuindo as chances de rejeição às ações de melhoria adotadas, respeitando a cultura da empresa e o tempo que as pessoas levam para se adaptar ao processo modificado. Com isso, o princípio "Integração Contínua" do XP é aplicado nesta atividade.

Templates: Não se aplica

\subsection{Fase 7 - Acompanhamento do Programa de Melhoria}

Esta fase tem como objetivo acompanhar a execução e evolução da abordagem, para medir os resultados da implantação de testes trazidos por ela, principalmente em relação aos objetivos da organização. Para isto, dados precisam ser coletados, organizados e analisados através de métricas estabelecidas.

Estabelecer Métricas: Nesta atividade, métricas devem ser identificadas pelos condutores e pela alta direção da organização. Estas métricas devem permitir avaliar se a organização alcançou os objetivos estabelecidos pelo programa. Um template com métricas básicas foi elaborado para facilitar a realização desta atividade. As métricas contidas no template foram definidas utilizando o paradigma GQM (Goal Question Metric Paradigm), criado por Basili [Basili, 1993].

Os objetivos que foram utilizados para derivação das métricas do template são objetivos organizacionais comumente encontrados em programas de melhoria. O template definido permite customizações, para cobrir objetivos que eventualmente não tenham sido cobertos pelo template padrão.

Coletar Métricas: nesta atividade as métricas devem ser coletadas para que na atividade seguinte elas sejam analisadas e seus resultados divulgados. Para a coleta, é necessário que seja definida a periodicidade, o responsável, o procedimento de análise e a unidade de medida para cada métrica. Um template de coleta de métricas foi elaborado a fim de facilitar a execução desta atividade. 
Avaliar e Divulgar Métricas: É importante que as métricas que foram coletadas sejam analisadas pelos responsáveis e seus resultados divulgados por toda a organização. Os resultados devem ser comparados com os dados atuais, para avaliar os benefícios que a abordagem trouxe para a organização.

Templates: Templates de Métricas Básicas, Template de Plano de Coleta de Métricas.

\section{Estudos de Caso}

As experiências, baseadas em estudo de caso, iniciaram durante a definição da abordagem AITS, auxiliaram sua definição e foram fundamentais para sua melhoria. Os dados gerados e os problemas enfrentados durante os estudos de caso permitiram analisar sua aplicabilidade no contexto de implantação e melhoria de testes de software e avaliar os resultados alcançados com sua execução. Durante o desenvolvimento da abordagem foram realizados dois estudos de casos, o primeiro estudo de caso juntamente com seus resultados pode ser visto em [Diniz et al, 2007]. O segundo estudo de caso realizado será detalhado abaixo.

\subsection{Estudo de Caso}

O segundo estudo de caso foi realizado numa empresa voltada para o desenvolvimento de projetos para os mais diversos setores. A empresa conta atualmente com aproximadamente 1200 colaboradores e possui a estrutura projetizada.

A abordagem AITS foi aplicada em um projeto desta organização que estava desenvolvendo uma ferramenta de gerência de projetos para uma multinacional do setor de telefonia. A escolha deste projeto para a aplicação da abordagem se deu, principalmente, porque o cliente era estratégico para a organização e se mostrava extremamente insatisfeito com a qualidade dos releases entregues pela equipe. Por causa disso, a alta direção tomou uma série de medidas que entre elas estavam a aplicação da abordagem AITS.

A equipe do projeto contava com a participação de 15 pessoas ao todo, sendo 10 engenheiros de sistemas, 4 engenheiros de teste e um gerente de projeto. Durante a aplicação da abordagem AITS, a empresa estava se preparando para ser avaliada no CMMI estagiado nível 3. O projeto escolhido não estava dentro do escopo da avaliação, mas mesmo assim deveria seguir uma customização do processo organizacional.

Neste estudo de caso foi utilizada a versão final da abordagem AITS, a fim de validar sua aplicação e comprovar os resultados obtidos. Para iniciar a aplicação da abordagem, o grupo de condutores foi estabelecido, sendo formado por dois membros da equipe de testes do projeto.

$\mathrm{Na}$ fase de Inicialização, foi obtido o comprometimento entre a alta direção, a gerente do projeto, que representava a alta direção da empresa, e o time independente de testes. Este comprometimento foi realizado através de uma reunião onde foram definidos dois objetivos da organização em relação ao programa de melhoria de testes do projeto: aumentar a qualidade do produto e aumentar a satisfação do cliente.

$\mathrm{Na}$ fase de Diagnóstico, o questionário de avaliação foi enviado via email para os membros que estavam direta ou indiretamente envolvidos com a área de testes. Os 
questionários preenchidos foram re-enviados para o time de condutores em um tempo médio de 2 dias. Entre os participantes da avaliação estavam todos os engenheiros de teste do projeto, um analista de requisitos e o gerente de projetos. Os resultados dos checklists de avaliação das entrevistas foram consolidados pelos condutores em um único checklist de avaliação. Na tabela 1 é apresentado resultado da avaliação.

\begin{tabular}{|l|c|c|}
\hline \multicolumn{3}{|c|}{ RESULTADO DA AVALIAÇÃO } \\
\hline \multicolumn{1}{|c|}{ PONTOS } & Nível 2 & Nível 3 \\
\hline Total de Pontos Válidos & 88 & 38 \\
\hline Total de Pontos Adquiridos & 33 & 14 \\
\hline RESULTADO & REPROVADO & REPROVADO \\
\hline
\end{tabular}

Tabela 1 - Resultado da avaliação do processo

Após a consolidação dos dados obtidos, o time de condutores realizou uma reunião, com participação do time do projeto, e a gerente como representante da alta direção da empresa. A apresentação tinha como objetivo exibir os pontos fortes e fracos existentes no processo de testes utilizado pelo projeto. Entre os principais pontos fortes levantados durante a avaliação estavam: existia um processo definido para planejamento, projeto, execução e análise de testes; a gerência de configuração do projeto funcionava de maneira adequada; um ambiente adequado para a realização das atividades de testes era fornecido; defeitos eram identificados e registrados no repositório de defeitos; treinamentos organizacionais em testes eram fornecidos.

Entre os principais pontos fracos levantados durante o diagnóstico estavam: embora houvesse um processo de testes definido, ele não era utilizado; testes funcionais e manuais eram realizados de forma exploratória, baseados apenas no conhecimento dos engenheiros de testes, não havia nada documentado; não existia planejamento de testes; testes não-funcionais não eram realizados; testes unitários não eram planejados, projetados e realizados; os requisitos não eram aprovados pelo stakeholders apropriados e os integrantes do time de testes não eram envolvidos apropriadamente; nenhuma métrica de testes estava definida.

Após o fim da fase de Diagnóstico, foi iniciada a fase de Planejamento de Ações de Melhoria. A primeira atividade desta fase foi selecionar as ações a partir do template de ações padrões. As ações selecionadas foram aquelas que endereçavam diretamente as deficiências de teste levantadas durante a avaliação. As ações selecionadas foram priorizadas de acordo com os critérios definidos na abordagem AITS.

Uma vez realizada a priorização das ações selecionadas, o plano de ação iterativo e incremental foi elaborado considerando as prioridades obtidas para cada ação. No plano de ação foram identificadas quatro iterações para todo o programa de melhoria. Este plano considerava ainda a realização de pilotos para prática e fixação do conhecimento adquirido durante a iteração. Um plano de ação mais detalhado com responsabilidades, marcos era elaborado no início de cada iteração. 
A fase seguinte, Implementar Ações de Melhorias, foi realizada de forma que toda a equipe de teste estivesse envolvida na execução das ações de melhoria planejadas para a iteração corrente. Ao final de cada iteração, os pilotos previstos foram realizados com sucesso. Devido ao tempo reduzido e à boa qualidade dos artefatos produzidos, os mesmos foram reaproveitados para no projeto real. Para a equipe de testes do projeto, isto foi um ponto positivo, pois ela estava produzindo e utilizando os artefatos, otimizando assim o tempo que eles tinham.

A fase Implementar Ações de Melhoria foi realizada 4 vezes durante o todo o programa de melhoria. A prática de automação dos testes prevista na última iteração planejada do plano de ação não foi realizada, pois não haveria continuação do projeto o que não justificava mais o esforço que seria gasto para implementação de tal prática. Desta forma, a gerência do projeto juntamente com um representante do time de teste optaram por implementar a prática caso houvesse uma continuação do projeto posteriormente. Entre a iteração 3 e 4 houve um período de aproximadamente 25 dias sem a realização do programa, isto se deve ao fato de que a equipe de testes estava muito sobrecarregada com as atividades do projeto e não podia dedicar $50 \%$ de sua carga horária para o programa de melhoria.

$\mathrm{Na}$ fase Verificar Resultados e Aprender, reuniões ao final da iteração foram realizadas com a equipe de testes, com a equipe de desenvolvimento, com a engenheira de qualidade e a gerente do projeto. As reuniões tinham duração de aproximadamente quatro horas. Todas as respostas eram exibidas e discutidas por todos os presentes na reunião. Ao final da reunião, um dos membros do time de condutores juntamente com a engenheira de qualidade reunia e compilava todas as informações para elas ficassem disponíveis para o time.

Ao final de cada iteração o conjunto de práticas que tiveram aceitação positiva pelo time de teste era agregado ao processo de teste customizado para o projeto, institucionalizando assim a melhoria no âmbito daquele projeto. A fase Acompanhar Melhoria foi realizada durante todo o programa de melhoria pela gerente do projeto e um membro do time de condutor. Como o gerente do projeto que era também representante da alta direção e estava muito próximo da equipe de condutores e testes, o acompanhamento do andamento do programa era realizado diariamente através de reuniões rápidas de 15 minutos. Com isso, não houve a necessidade de métricas de acompanhamento do programa de melhoria.

A fase Implementar Ações foi a que mais consumiu esforço na aplicação da abordagem. Isto se deve, principalmente, ao fato da equipe de testes ter tido um tempo muito reduzido para realização de atividades do projeto real, o que acabou muitas vezes impactando nas atividades e nas horas do projeto do programa de melhoria, aumentando assim os prazos para finalização das atividades no projeto piloto. Para este estudo de caso, o custo para implementação e melhoria do processo customizado também foi considerado baixo pela organização em relação à capacidade produtiva da empresa e os benefícios trazidos por ela.

Ao final do programa de melhoria, o diagnóstico do processo de teste foi realizado novamente com o objetivo de verificar sua evolução com a implementação da abordagem AITS. A tabela 2 exibe o resultado da avaliação após a implementação da AITS. 


\begin{tabular}{|l|c|c|}
\hline \multicolumn{3}{|c|}{ RESULTADO DA AVALIAÇÃO } \\
\hline \multicolumn{1}{|c|}{ PONTOS } & Nível 2 & Nível 3 \\
\hline Total de Pontos Válidos & 84 & 40 \\
\hline Total de Pontos Adquiridos & 68 & 34 \\
\hline RESULTADO & PASSOU & PASSOU \\
\hline
\end{tabular}

Tabela 2 - Resultado Final da Avaliação do Processo

Como pode ser observado através da tabela 2, o processo conseguiu atingir o nível 2 e o nível 3 do TMM. Com isso temos ao final do programa de melhoria um processo de testes que atende a $81 \%$ do nível 2 e $85 \%$ do nível 3 TMM representando uma melhoria de $43 \%$ e $48 \%$ respectivamente. Algumas melhorias ainda precisarão ser realizadas para que o processo atenda por completo as práticas nível 2 e 3 do TMM, principalmente porque as práticas relacionadas com a automação de testes não foram implementadas, impactando assim na área Execução de Teste.

Além da avaliação do processo em relação ao TMM, um indicador foi estabelecido e coletado ao longo do programa para verificar a eficiência do time de teste. A tabela 3 exibe a quantidade de bugs identificados antes e durante a implementação da abordagem AITS.

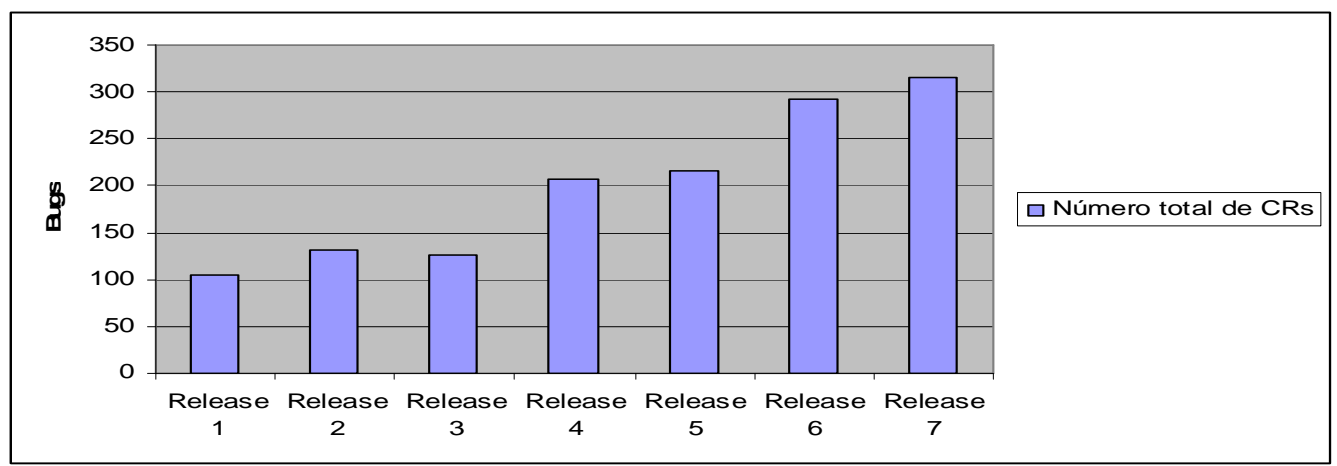

Tabela 3 - Número de bugs antes e durante a AITS

Como pode ser observado no gráfico acima, a quantidade de bugs identificados pelo time de teste após a implantação da abordagem AITS (após Release 3) aumentou consideravelmente. O que pode indicar um aumento na qualidade no produto entregue já que mais defeitos foram identificados antes do produto chegar ao cliente. A satisfação do cliente também aumentou consideravelmente ao longo do projeto, se antes da aplicação da abordagem a satisfação do cliente era em média 3,0 ao final da aplicação da abordagem esta satisfação atingiu a média 4,5 , sendo que a pontuação máxima possível era 5,0. Além disso, ao final do projeto foi enviado um questionário para os dois representantes do cliente, a fim de analisar suas percepções em relação à qualidade final do produto e como a equipe de testes pode ter influenciado nisto. Os dois representantes do cliente consideraram que a equipe de teste influenciou muito positivamente na qualidade do produto final. Além disso, outro ponto bastante enfatizado por eles foi o envolvimento do time de testes na revisão dos requisitos, ajudando no entendimento das regras de negócio e com isso, realizando testes mais eficazes. Em relação ao time do 
projeto, um questionário com mais questões foi enviado para alguns membros da equipe a fim de coletar a percepção deles em relação aos benefícios trazidos pelas mudanças realizadas no time de teste. A grande maioria dos entrevistados respondeu que as mudanças realizadas ao longo do projeto impactaram diretamente na melhora da qualidade do produto entregue ao cliente. Ao final da aplicação da abordagem, a alta direção e a equipe de testes das empresas participantes, consideraram a abordagem como sendo uma boa alternativa para a realização de implantação e/ou melhoria de processo de testes. As principais vantagens listadas por eles em relação à AITS foram: baixo custo de implementação, simples e de fácil entendimento, resultados alcançados em um curto espaço de tempo, participação de toda a equipe de testes na implementação de novas práticas, baixa resistência das equipes envolvidas.

Assim, pelos resultados obtidos dos estudos de casos, pode-se dizer que a abordagem AITS se mostra uma boa alternativa para organizações que desejam alcançar melhores resultados na qualidade do produto e na satisfação dos clientes.

Apesar disso, algumas dificuldades foram encontradas ao longo da implantação da abordagem AITS nos estudos de caso relatados, tais como: grande resistência inicial por parte de outras equipes na implantação da abordagem AITS; conflitos entre iniciativas nas empresas, as duas empresas estavam realizando outras iniciativas em melhoria de software, o que, muitas vezes, impedia grandes alterações em seus processos de teste; em um dos projetos, houve reaproveitamento dos artefatos dos projetos pilotos devido à limitação de tempo; houve interrupção do programa de melhoria por sobrecarga da equipe no projeto real.

\section{Conclusão}

Este trabalho apresentou a abordagem AITS, cujo objetivo é contribuir para a melhoria de processo de teste de software em organizações de desenvolvimento de software, através da implantação e melhoria de processos de teste baseada em práticas ágeis, considerando suas características e limitações.

O grande benefício deste trabalho é prover uma alternativa às empresas, que desejam melhorar seus processos e a qualidade dos seus produtos.

Através da implantação desta abordagem a melhoria de processos de testes é alcançada de forma gradual, minimizando a resistência das pessoas afetadas, aproveitando os recursos internos da organização, motivando os envolvidos com resultados em curto prazo, evitando abandono do programa de melhoria por falta no entendimento do modelo e evitando adaptações na abordagem para sua aplicação.

Em relação aos modelos existentes, a abordagem AITS apresenta as seguintes diferenças:

- Necessita a criação de somente um grupo específico dentro da organização para a implementação/melhoria do processo de teste, que é o time de condutores. Além disso, este time conta com a participação dos próprios colaboradores da organização. Isto faz com que os custos do programa de melhoria sejam reduzidos, já que não há necessidade de contratação de uma consultoria externa e nem há um alto número de funcionários alocados em atividades do programa de melhoria; 
- Incorpora muitas práticas/princípios ágeis que a torna mais simples e ágil, contando com a presença de um conjunto mínimo de atividades necessárias para a realização de um programa de melhoria, com templates que apóiam a realização das atividades e com um vocabulário simples, evitando más interpretações;

- É específica para o contexto de testes unindo os benefícios trazidos pelos principais modelos de melhoria de processo e por um modelo de maturidade em testes TMM. Conta ainda com os templates elaborados especificamente para o contexto de melhoria de processo de testes, possuindo ao mesmo tempo o "como fazer" e "o que fazer" para melhorar um processo de teste em uma organização;

- Elaborada considerando as principais limitações e dificuldades enfrentadas pelas empresas de software em um programa de melhoria possuindo investimento compatível com a realidade das empresas e possibilitando a visualização de resultados em um curto espaço de tempo;

- O processo de avaliação contido na abordagem é bastante simplificado se comparado aos processos de avaliação dos modelos de melhoria apresentados. Conta ainda com o apoio de um template que calcula automaticamente o nível do TMM que a organização se encontra baseado nas respostas dadas pelos entrevistados, minimizando assim as chances de erros inerentes a este processo.

- A abordagem se mostrou muito atrativa para as organizações utilizadas por ser extremamente simples; é específica para o contexto de teste de software, evitando trabalho com grandes adaptações da abordagem.

\section{Referências}

[Basili, 1993] BASILI, V. R., CALDIERA G., ROMBACH H. D., "The Goal Question Metric Approach", University of Maryland, 1993

[Beck, 1999] BECK, K.; ANDRES, C. Extreme Programming explained: embrace change. 1. ed. Upper Saddle River: Addison-Wesley, 1999. 189 p.

[Brodman, 1994] BRODMAN, J.G.; JOHNSON, D.L. "What Small Business and Small Organisations say about CMM?" Procedings of the 16th International Conference on Software Engineering, Sorrento, Italy, May 1994.

[Burnstein, 2003] BURNSTEIN, I. Practical software testing : a process-oriented approach. Springer-Verlag New York, Inc, 2003.

[Carosia, 2003] CAROSIA, J.S. Levantamento da qualidade do processo de software com foco em pequenas organizações. Dissertação de Mestrado. Instituto Nacional de Pesquisas Espaciais, 2003.

[Diniz et al, 2007] DINIZ, R.; OCHNER, J. Implantação de uma Metodologia de Testes em Iterações para um Grupo Independente. Relato de Experiência, SBQS - Simpósio Brasileiro de Qualidade de Software, 2007.

[Ericson, 1996] ERICSON, T., SUBOTIC A. A Test Improvement Model. Artigo Técnico - EUROSTAR, 1996. 
[Freesz, 2004] FREESZ. E.V., Melhoria do processo de teste com TMM em uma grande empresa. Trabalho de Especialização em Melhoria de Processo de Software, Universidade Federal de Lavras, 2004.

[Humphrey, 1989] HUMPHREY W., Managing the Software Process - Addison Wesley Professional, Massachusetts, 1989.

[ISO15504, 2005] Internacional Organization for Standarlization. ISO/IEC 15504: Information Technology Process Assessment, Part 1 to Part 5. ISO/IEC International Standard, 2003-2005.

[Koomen, 1999] KOOMEN, T.; POL, M. Test Process Improvement: A practical Step by Stepguide to structured testing, Addison-Wesley, 1999.

[McFeeley, 1996] McFEELEY, R. IDEAL: A User's Guide for Software Process Improvement. Relatório Técnico CMU/SEI-96-HB-001, Software Engineering Institute, 1996.

[MCT_01, 2001] MINISTÉRIO DA CIÊNCIA E TECNOLOGIA. Qualidade e Produtividade no Setor de Software Brasileiro: Resultados da Pesquisa 2001. Disponível em: http://www.mct.gov.br/Temas/info/Dsi/Quali2001/Public2001.htm Acesso em: 28 nov. 2007.

[Niasi, 2003] NIAZI, M.; WILSON D.; ZOWGHI Didar. A model for the implementation of software process improvement: A pilot study. Artigo Técnico. Proceedings of the Third International Conference On Quality Software (QSIC'03). IEEE Software, 2003.

[Reffson, 2006] REFFSON A.; BEZERRA C.I.; COUTINHO E. Análise da Aderência de um Processo de Teste ao TMM. Artigo Técnico, SBTS - I Simpósio Brasileiro de Teste de Software, 2006.

[Salviano, 2006] SALVIANO, C. F.; Uma Proposta orientada a Perfis de Capacidade de Processo para Evolução da Melhoria de Processo de Software. Tese de Doutorado, Universidade Estadual de Campinas, 2006.

[Santana, 2007] SANTANA, A.F., Problemas em Iniciativas de Melhoria de Processos de Software sob a Ótica de uma Teoria de Intervenção. Dissertação de Mestrado, Universidade Federal de Pernambuco, 2007.

[Santos, 2006] SANTOS J.; ALVES G. TMM-e Framework. Artigo Técnico, SBTS - I Simpósio Brasileiro de Teste de Software, 2006.

[Schwaber, 2004] SCHWABER, K. Agile Project Management with Scrum. 1 ed. Microsoft Press, WA, 2004.

[Vasconcelos et al, 2006] VASCONCELOS, A. M.; ROUILLER, A.C. et al. Introdução à Engenharia de Software e à Qualidade de Software. Lavras: UFLA/FAEPE, 2006. 